\title{
BMJ Open Does the person's context influence engagement in life activities following primary knee replacement? Results from a Canadian prospective cohort study
}

\author{
Aileen M Davis, ${ }^{1,2}$ Viji Venkataramanan, ${ }^{1}$ Jessica Bytautas-Sillanpää, ${ }^{1,3}$ \\ Anthony V Perruccio, ${ }^{1,2}$ Rosalind Wong, ${ }^{1}$ Lisa Carlesso, ${ }^{1,4}$ Fiona Webster ${ }^{5}$
}

To cite: Davis AM, Venkataramanan V, BytautasSillanpää J, et al. Does the person's context influence engagement in life activities following primary knee replacement? Results from a Canadian prospective cohort study. BMJ Open 2017;7:e015737. doi:10.1136/ bmjopen-2016-015737

- Prepublication history for this paper is available online. To view these files please visit the journal online (http://dx.doi org/10.1136/bmjopen-2016015737).

Received 23 December 2016 Revised 8 June 2017 Accepted 28 June 2017

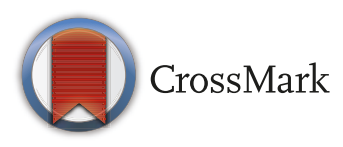

For numbered affiliations see end of article.

Correspondence to

Dr Aileen M Davis; adavis@uhnresearch.ca

\section{ABSTRACT}

Objective The impact of the context of a person's life on recovery from surgical interventions is not well understood. This study evaluated if people's social, environmental and biomedical context was associated with change in frequency in engagement in life activities after total knee replacement (TKR).

Methods 418 people aged 30+ years who had TKR were followed presurgery to 1 year postsurgery. The outcome was change in frequency in engagement in life activities measured by the Late Life Disability Index (LLDI). Predictor variables of interest evaluated in multivariable linear regression analysis were positive and negative life events (Life Experiences Survey), development of a new comorbidity, another joint replacement and complications after TKR surgery.

Results Mean age was 65 years, $36 \%$ were male; $22 \%$ and $21 \%$ had no comorbidity presurgery and postsurgery. Presurgery LLDI frequency was $69.6( \pm 11.4)$ and the mean change was $6.1( \pm 10.2)$. Thirty-four per cent and $65 \%$ reported at least one positive or negative life event. Seven per cent developed hypertension, $6 \%$ cardiovascular disease, $2 \%$ lung disease and $2 \%$ diabetes. Eleven per cent had a complication and $9 \%$ another hip or knee replaced. Smaller changes in LLDI frequency were associated with more negative life events (beta $=-0.56 ; 95 \% \mathrm{Cl}-0.92$ to- 0.18 ) and complications (beta $=-4.01 ; 95 \% \mathrm{Cl}-6.63$ to -1.38 ) after adjusting for age, sex, education, body mass index, comorbidities presurgery, number of symptomatic joints and kneespecific pain and function, LLDI limitations and depression. A new comorbidity or another joint replacement was not associated with outcome in unadjusted or adjusted analysis.

Conclusions Multifaceted life experiences shape the context of peoples' lives impacting their engagement in activities important for healthy living post-TKR.

\section{INTRODUCTION}

People's experiences of and outcomes of healthcare can be influenced by the context of their life. The WHO's International Classification of Functioning, Disability and Health identifies personal and environmental
Strengths and limitations of this study

- First prospectively collected cohort data to evaluate the association of the person's life context on change in frequency in engagement in life activities following total knee replacement.

- The association of both positive and negative life events are considered which is contrary to much of the literature in chronic disease that considers only negative events (ie, stressors).

- Participant recruitment from tertiary care centres may limit generalisability.

Secondary analyses of self-report data.

factors as influencing people's experiences of disability. ${ }^{1}$ Theory and current discussions of client-centred or person-centred care similarly recognise the relevance of the person's context. ${ }^{2-6}$ Despite a focus on client-centred care over the last two decades, much research has focused on patient-provider communication or patient satisfaction with care provision. Recent critiques have established that there is a gap between 'the rhetoric of patient-centred care and the experience of many patients and families in modern healthcare systems'. ${ }^{7}$ We found little or no research that considers the context of the person's life, specifically related to social, environmental and biomedical impactful life events, in the recovery from medical or surgical interventions.

Osteoarthritis (OA) is a common chronic condition and is associated with pain and functional disability, ${ }^{8}$ consequences that limit mobility and engagement in life activities. Recent data demonstrate the negative impact of limited mobility and activity from OA on the development and control of chronic conditions like cardiovascular disease and diabetes and on mortality in people with OA. ${ }^{9-11}$ For those with moderate to severe knee OA, 
primary total knee replacement (TKR) results in large improvements in pain, daily function and mobility for most people. ${ }^{12}{ }^{13}$ However, there are minimal increases in the frequency of participation in life activities in the year following surgery, ${ }^{14}$ a time when improvements in pain and function after TKR have stabilised. ${ }^{15-17}$ Smith et al also described the negative effects of living with OA on participation in social and recreational activities, including loss of identity, social stigma and isolation. ${ }^{18}$ Engagement in life activities that includes participation in instrumental activities of daily living, personal (eg, managing personal health, errands, household business) and social roles (eg, visiting friends/family, social activities, active recreation and exercise) is critical to healthy ageing and managing chronic illness. Such a lifestyle improves mental, physical and overall well-being and decreases healthcare utilisation. ${ }^{19-24}$ Additionally, as we increasingly move to personalised medicine, understanding engagement in life activities may serve as motivation for setting personal goals so that people can regain important activities that give value and meaning to life.

In a longitudinal qualitative study, our group found that both health-related and non-health-related factors impacted engagement in life activities after TKR. People reported limiting their engagement in many physical, social and leisure activities long before surgery, had a surgical complication, developed new comorbidity and experienced significant life events (eg, death or declining health of a close family member or friend, moving residence, etc) following surgery. ${ }^{25}$ These qualitative findings highlight how the context of people's lives interacts with and can influence their health outcomes and healthcare experience.

The TKR population is likely an ideal group in which to evaluate the impact of the person's context on engagement in life activities given the effectiveness of the surgery in relieving pain and improving function. Informed by our qualitative work, ${ }^{25}$ the purpose of the current study was to (1) describe people's frequency of engagement in life activities presurgery and postsurgery and the life events experienced in the year postsurgery and (2) determine if these events were associated with change in frequency in engagement in life activities a year following TKR.

\section{METHODS}

We conducted a prospective cohort study of people with primary TKR for OA recruited between 2005 and 2008 from four tertiary care centres in Toronto, Canada. The primary objective of the study was to understand the trajectory of recovery in relation to symptoms, function and participation in social and leisure activities in people with total hip replacement and TKR in the first year following surgery. ${ }^{14}$ Individuals were eligible if they were between the ages of 18 and 85 years, were having primary hip or knee joint replacement for OA, were fluent in English to allow survey completion and consented to participate. The current study addresses a secondary objective and includes people from this cohort with TKR who had presurgery (within 1 month of surgery) and 1 year postsurgery data for our primary outcome measure, the Late Life Disability Index (LLDI) frequency dimension. ${ }^{26}$ All data were collected by patient-completed questionnaire. This research was approved by the institutional ethics review board of each participating centre and conformed to the principles of the Declaration of Helsinki.

\section{Primary outcome}

The reliable and valid LLDI includes 16 socially defined life tasks, including social, leisure, exercise and household and personal management roles, with summary scores for two disability dimensions, limitations in capability and frequency of performance. The primary outcome for this study was change in frequency in engagement in life activities based on the frequency in performance dimension scale. ${ }^{26}$ Respondents indicated how often they engaged in these life tasks on a scale ranging from 1 (never) to 5 (very often). Based on fit of the data to the Rasch model, raw scores are transformed to interval level scores ranging from 0 to 100 with higher scores indicating greater frequency. The intraclass correlation coefficient for test-retest reliability was 0.7 . For our outcome, change in frequency of engagement in life activities, change scores were calculated as the difference between the 1-year follow-up and presurgery scores of the LLDI frequency dimension.

\section{Predictor variables}

Informed by our prior qualitative study, ${ }^{25}$ our predictor variables of interest were positive and negative life events, development of at least one new comorbidity, complications post index TKR and another joint replacement over the course of the year following surgery.

Life events were captured at 3, 6 and 12 months following TKR using the reliable and valid modified Life Experiences Survey. ${ }^{27}$ The 12-item survey includes events which sometimes result in change in the life of those experiencing the event, necessitating social readjustment. The survey includes events such as marriage, marital separation, marital reconciliation, change of residence, change of work situation, retirement from work, major personal illness/injury, serious illness/injury of a family member, serious illness/injury of a close friend, death of a spouse/close family member or friend, major change in financial status and major change in social activities. The individual indicates if an event has occurred in the past 3 months (no/yes). If 'yes', they indicate the extent of impact on their life on a seven-point scale ranging from $-3=$ extremely negative $(0=$ no impact $)$ to $+3=$ extremely positive. Test-retest reliability was reported using Pearson's correlation coefficients and were 0.5 for positive events and 0.9 for negative events. There were no significant differences in positive or negative life event scores for males and females. Additionally, construct validity was supported as negative life events correlated with anxiety (correlations $0.3-0.5, \mathrm{p}<0.01$ ), whereas positive life events 
did not have statistically significant correlations with anxiety as hypothesised. For our analyses, we calculated a count for each of the positive and negative life events experienced over the course of the year postsurgery irrespective of when it occurred (ie, an event was only counted once within the year), providing the individual indicated that the event was impactful.

A new comorbidity was identified during follow-up by 'yes' responses to the valid American Academy of Orthopaedic Surgeon's Comorbidity scale ${ }^{28}$ where a 'no' response was previously reported. We also categorised the number of new comorbidities (range 1-4 per person) as an alternate definition as some literature suggests that cumulative stressors (eg, illness, negative life events) may be relevant. ${ }^{2930}$

Replacement of another hip or knee was captured by a 'yes' response to a question asking if the individual had surgery on another hip or knee and, if yes, if they had the joint replaced.

Complications postsurgery were collected at 3 months follow-up. Participants responded no/yes to each of knee dislocation, infection, blood clot and other with a textual explanation requested. Each of a new comorbidity, joint replacement surgery and complication were coded as no/yes for analysis.

\section{Covariates}

A number of factors have been associated with outcome following TKR: age, sex, education, living alone, body mass index (BMI), number of symptomatic joints presurgery, comorbidity, depression presurgery and presurgery pain and function. ${ }^{31}$ Our prior work also indicated that the presurgery limitations in capability in socially derived tasks as measured by the LLDI limitation dimension scale was associated with outcome. ${ }^{14}$

Education was coded as $\leq$ high school versus $>$ high school and lives alone as no/yes. The number of symptomatic joints was determined from a homunculus where the individual indicated if they experienced pain, stiffness or swelling on most days of the past month. Age and BMI were treated as continuous variables.

Patient-reported outcome measures were used for a number of covariates. We measured presurgery pain and function by the reliable and valid Western Ontario McMaster Universities Osteoarthritis Index (WOMAC), ${ }^{33}$ and depression was measured by the depression subscale of the Hospital Anxiety and Depression Scale (HADS). ${ }^{34}$ Limitations in life activities were evaluated presurgery with the LLDI limitation subscale. ${ }^{26}$ The LLDI limitation subscale is scored $0-100$ with higher scores representing less limitation as noted above for the frequency dimension scale, whereas the WOMAC pain and function subscales are scored $0-20$ and $0-68$, respectively, with lower scores representing less pain and functional limitations. Depression was scored 0-21 where higher scores represent more depressive symptoms.

Missing values for standardised measures were imputed using the developer guidelines. For consistency and to aid in interpretation when change scores were modelled, the WOMAC and HADS scores were reversed so that positive scores for all measures represented improvement.

\section{Analysis}

Descriptive statistics were calculated for all variables using proportions, means and SD as appropriate to the type of data. We used multivariable linear regression analysis to determine if our variables of interest, positive and negative life events, complications, another joint replacement and new comorbidity were associated with change in LLDI frequency as a continuous variable. Finally, this model was adjusted for the covariates identified above that have been associated with outcome following TKR: age, sex, education, living alone, BMI, number of symptomatic joints presurgery, comorbidity, depression presurgery and presurgery pain, function and limitations in socially defined tasks. All model assumptions were evaluated and confirmed.

As the missing data were less than $7 \%$ (5\% for any individual variable) (table 1), we modelled the data as a complete case analysis.

\section{RESULTS}

The original cohort included 494 people with TKR but, excluding those who did not have a presurgery or 1-year follow-up of the LLDI frequency dimension scale which precluded calculation of the change score for our primary outcome, the sample in the current study was 418. Table 1 shows that the characteristics of those excluded are similar to the included participants. The 418 individuals had an average age of 65 years; $64 \%$ were female and most had greater than high school education $(69 \%)$. On average, people were obese (ie, BMI $>30$ ) and $78 \%$ reported comorbidity presurgery. Only $20 \%$ of the sample reported symptoms restricted to their operative knee, with participants reporting four symptomatic joints on average. Table 1 shows the presurgery sample descriptive data.

The mean presurgery LLDI frequency dimension score was $70(\mathrm{SD}=11.4)$. The average change in frequency of the LLDI by 1 year postsurgery, our primary outcome, averaged 6.1 points $(\mathrm{SD}=10.2)$.

Table 1 also provides details related to our predictor variables of interest, the development of new comorbidities, life events, new hip or knee replacement and complications from the index.

While a similar proportion of people reported no comorbidity presurgery $(\mathrm{n}=92 ; 22 \%)$ and through follow-up $(n=86 ; 21 \%), 161$ individuals $(38 \%)$ reported at least one new comorbidity in the year following surgery. Small numbers of people reported new hypertension $(29(7 \%))$, cardiovascular disease $(27(6 \%))$, diabetes $(8$ $(2 \%))$ or lung conditions $(10(2 \%))$. 'Other' comorbidities included low back pain $(n=72)$, depression $(n=27)$, and haematological conditions $(n=21)$. 
Table 1 Sample descriptive data and measures

\begin{tabular}{|c|c|c|c|c|}
\hline & \multirow{2}{*}{$\begin{array}{l}\text { Exclusions }(\mathrm{n}=86) \\
\text { Presurgery }\end{array}$} & \multicolumn{3}{|c|}{ Included sample $(n=418)$} \\
\hline & & Presurgery & & Postsurgery \\
\hline Variables & & $\begin{array}{l}\text { Mean }( \pm S D) \text { or } \\
\mathrm{n} \text { (percentage) }\end{array}$ & & $\begin{array}{l}\text { Mean }( \pm S D) \text { or } \\
\mathrm{n} \text { (percentage) }\end{array}$ \\
\hline Age $(n=418)$ & $67.7( \pm 7.1)$ & $65.0( \pm 10.0)$ & & - \\
\hline Sex $(n=418):$ Male & $17(20 \%)$ & $151(36 \%)$ & & - \\
\hline $\begin{array}{l}\text { Education }(n=418) \text { : greater } \\
\text { than high school }\end{array}$ & 52 (69\%) & $289(69 \%)$ & & - \\
\hline Lives alone $(n=418)$ & $34(40 \%)$ & $104(25 \%)$ & & \\
\hline $\begin{array}{l}\text { Number of symptomatic } \\
\text { joints }(n=418)\end{array}$ & $2.9( \pm 3.0)$ & $3.9( \pm 3.7)$ & & \\
\hline Comorbidities $(n=418)$ & & & Comorbidities $(n=418)$ & \\
\hline No comorbidities & $16(19 \%)$ & $92(22 \%)$ & No comorbidities & $86(21 \%)$ \\
\hline \multirow[t]{2}{*}{ At least one comorbidity } & $70(81 \%)$ & $326(78 \%)$ & At least one comorbidity & $332(79 \%)$ \\
\hline & & & At least one new comorbidity & $161(38 \%)$ \\
\hline Hypertension & - & $206(49 \%)$ & Hypertension & $29(7 \%)$ \\
\hline Cardiovascular & - & $26(6 \%)$ & Cardiovascular & $27(6 \%)$ \\
\hline Diabetes & - & $55(13 \%)$ & Diabetes & $8(2 \%)$ \\
\hline Lung disease & - & $51(12 \%)$ & Lung disease & $10(2 \%)$ \\
\hline Other* & - & $208(50 \%)$ & Other* & $118(28 \%)$ \\
\hline BMI $(n=402)$ & $32.1( \pm 5.0)$ & $30.6( \pm 7.0)$ & & - \\
\hline LLDI frequency $(n=418)$ & & $69.6( \pm 11.4)$ & Frequency changet( $(n=418)$ & $6.1( \pm 10.2)$ \\
\hline LLDI I3imitation (n=395) & & $69.9( \pm 16.5)$ & Limitation changet(n=395) & $15.9( \pm 15.7)$ \\
\hline WOMAC pain $(n=416)$ & & $10.2( \pm 3.5)$ & Pain change $+(n=416)$ & $6.9( \pm 3.8)$ \\
\hline WOMAC function $(n=415)$ & & $33.0( \pm 12.5)$ & Function change $+(n=415)$ & $19.4( \pm 12.1)$ \\
\hline \multirow[t]{8}{*}{$\begin{array}{l}\text { Depression subscale } \\
(n=416)\end{array}$} & & $5.0( \pm 3.4)$ & $\begin{array}{l}\text { Depression change } \dagger(n=416) \\
\text { Life events (within a year) } \ddagger(n=418)\end{array}$ & $1.7( \pm 3.2)$ \\
\hline & & & Positive impact events & $144(34 \%)$ \\
\hline & & & Negative impact events & $273(65 \%)$ \\
\hline & & & New joint replacement $(n=418)$ & 39 (9\%) \\
\hline & & & $\begin{array}{l}\text { Complications from index surgery } \\
(\mathrm{n}=418)\end{array}$ & $47(11 \%)$ \\
\hline & & & Knee dislocation & $2(0.5 \%)$ \\
\hline & & & Infection & $31(7 \%)$ \\
\hline & & & Deep vein thrombosis & $14(3 \%)$ \\
\hline
\end{tabular}

*These include cancer (excluding skin cancer), renal disease, low back pain, depression, stroke, liver disease, anaemia or other blood disease and ulcers.

†Change scores are calculated so that positive scores represent improvement for all measures to aid interpretation. $\ddagger$ Number of participants who experienced one or more positive or negative life events.

BMI, body mass index; LLDI, Late Life Disability Index; WOMAC, Western Ontario McMaster Universities Osteoarthritis Index.

Surgical complications were reported by $47(11 \%)$ people and $39(9 \%)$ had another knee $(\mathrm{n}=36)$ or a hip $(n=3)$ replaced over the course of the year.

Impactful life events were frequent with 144 (34\%) participants reporting at least one positive event and $273(65 \%)$ reporting at least one negative event. Overall, the 418 participants reported a total of 244 positive and 629 negative life events. As shown in table 2, the most frequently reported positive events were changes in social activities (56 participants), work situation (46 participants) and financial status (30 participants). The most frequently reported negative events were death of a spouse, family member or close friend (129 participants), serious illness of a close family member (111 participants) and major change in social activities (92 participants). Of note, the same event (eg, divorce) was reported as a negative event by some respondents and as a positive event by other respondents.

Table 1 also includes the descriptive data for the covariates used in the adjusted linear regression analysis. 
Table 2 Postsurgery $(n=418)$ incidence of positive and negative life events

\begin{tabular}{|c|c|c|c|c|}
\hline \multirow[b]{2}{*}{ Life event } & \multicolumn{2}{|c|}{$\begin{array}{l}\text { Positive life } \\
\text { events }\end{array}$} & \multicolumn{2}{|c|}{$\begin{array}{l}\text { Negative life } \\
\text { events }\end{array}$} \\
\hline & $\mathbf{n}$ & $\%$ & $\mathbf{n}$ & $\%$ \\
\hline Marriage & 5 & 1.2 & 3 & 0.7 \\
\hline Marital separation* & 3 & 0.7 & 6 & 1.4 \\
\hline Marital reconciliation & 4 & 0.1 & 3 & 0.7 \\
\hline Change of residence & 19 & 4.5 & 7 & 1.7 \\
\hline Changed work situation $†$ & 47 & 11.2 & 42 & 10.0 \\
\hline Retirement from work & 16 & 3.8 & 12 & 2.9 \\
\hline Major personal illness/injury & 13 & 3.1 & 72 & 17.2 \\
\hline $\begin{array}{l}\text { Serious illness of close family } \\
\text { member }\end{array}$ & 18 & 4.3 & 111 & 26.5 \\
\hline $\begin{array}{l}\text { Serious illness/injury of close } \\
\text { friend }\end{array}$ & 9 & 2.1 & 61 & 14.6 \\
\hline Death $\ddagger$ & 25 & 6.0 & 129 & 30.9 \\
\hline $\begin{array}{l}\text { Major change in financial } \\
\text { status§ }\end{array}$ & 30 & 7.2 & 91 & 21.8 \\
\hline $\begin{array}{l}\text { Major change in social } \\
\text { activities }\end{array}$ & 56 & 13.4 & 92 & 22.0 \\
\hline
\end{tabular}

*Due to conflict.

†Example: different work responsibility, major change in working conditions/hours.

$\ddagger$ Spouse, close family member or friend.

$\S$ Lot better off or lot worse off.

||Example: parties, movies, visiting - increased or decreased participation.

Table 3 provides the results of the unadjusted and adjusted linear regression analyses. In unadjusted analysis, negative life events and surgical complications were significantly associated with change in LLDI frequency. Positive life events, at least one new comorbidity, and another knee or hip replacement were not significantly associated with change in frequency. Defining a new comorbidity by the number of new comorbidities did not change the results.

These findings were consistent after adjusting for covariates. That is, negative life events and surgical complications were associated with smaller change in LLDI frequency. Additionally, people with more symptomatic joints had smaller change in LLDI frequency.

\section{DISCUSSION}

This study found that negative life events, surgical complications and having multiple symptomatic joints were associated with smaller change in frequency in engagement in socially constructed life tasks following TKR. These findings suggest that what is happening in people's lives as well as health-related factors impact people's frequency in engagement in life activities following a common elective surgery, TKR.
The concept of client-centred care continues to be the topic of much discussion and debate. Berwick proposed the following definition of patient-centred care ${ }^{35}$ :

'The experience (to the extent the informed, individual patient desires it) of transparency, individualization, recognition, respect, dignity, and choice in all matters, without exception, related to one's person, circumstances, and relationships in healthcare'.

While studies have looked at aspects of client-centredness, ${ }^{2-6}$ this is the first study to our knowledge that has elucidated the extent to which what is happening in a person's life, that is, their 'circumstances' or social, environmental and biomedical context, impact the change in frequency of engagement in life activities that promote healthy ageing following a common elective surgical procedure, TKR. The results in part support our prior qualitative findings of the complexity of the patient experience of health and healthcare during recovery from TKR. ${ }^{25}$ In this cohort, with pain and function outcomes similar to what is reported in the literature, ${ }^{36} 37$ this complexity arose not only from the surgical recovery but also from sociocultural factors, particularly various life events and the development of surgical complications following the index TKR. Additionally, other symptomatic joints negatively influenced change in frequency in engagement.

Life events, particularly stressors, have been evaluated in other chronic conditions such as diabetes. These works have focused on a specific disease outcome, usually diagnosis or prevalence/incidence of the disease. ${ }^{38-40}$ In one study evaluating disease management, Bradley found that stressful life events were associated with problems managing type II diabetes. ${ }^{38}$ However, we did not identify any studies that addressed a broader conceptual outcome like engagement in life activities as this work has done. Additionally, none of these works considered positive events as well as stressors (or negative life events).

The strength of this study is that the conceptualisation and analytic approach were guided by prior qualitative work. However, there are several limitations. All of our data were self-report and we did not verify the reporting of new comorbidity or life events. There also may be some limitations to generalisability. Participants were recruited from academic tertiary care centres, although research does show that the outcomes of people with hip and knee replacement are similar in academic and community care centres. ${ }^{41}$ Additionally, a Canadian sample may differ from those in other countries, particularly in their perceptions and experiences of life events.

Impactful life events were reported by a large proportion of the cohort in the 12 months following surgery with twice as many people reporting at least one negative $(65 \%)$ as compared with positive event $(34 \%)$. While one might expect negative events for a cohort with average age of 65 years, we were surprised by the overall number of negative impactful events experienced in a single year. In a cross-sectional population-based study from Hong Kong $(\mathrm{n}=1147)$ with mean age 53.2 years $(\mathrm{SD}=19.6),{ }^{42} 53.4 \%$ reported 


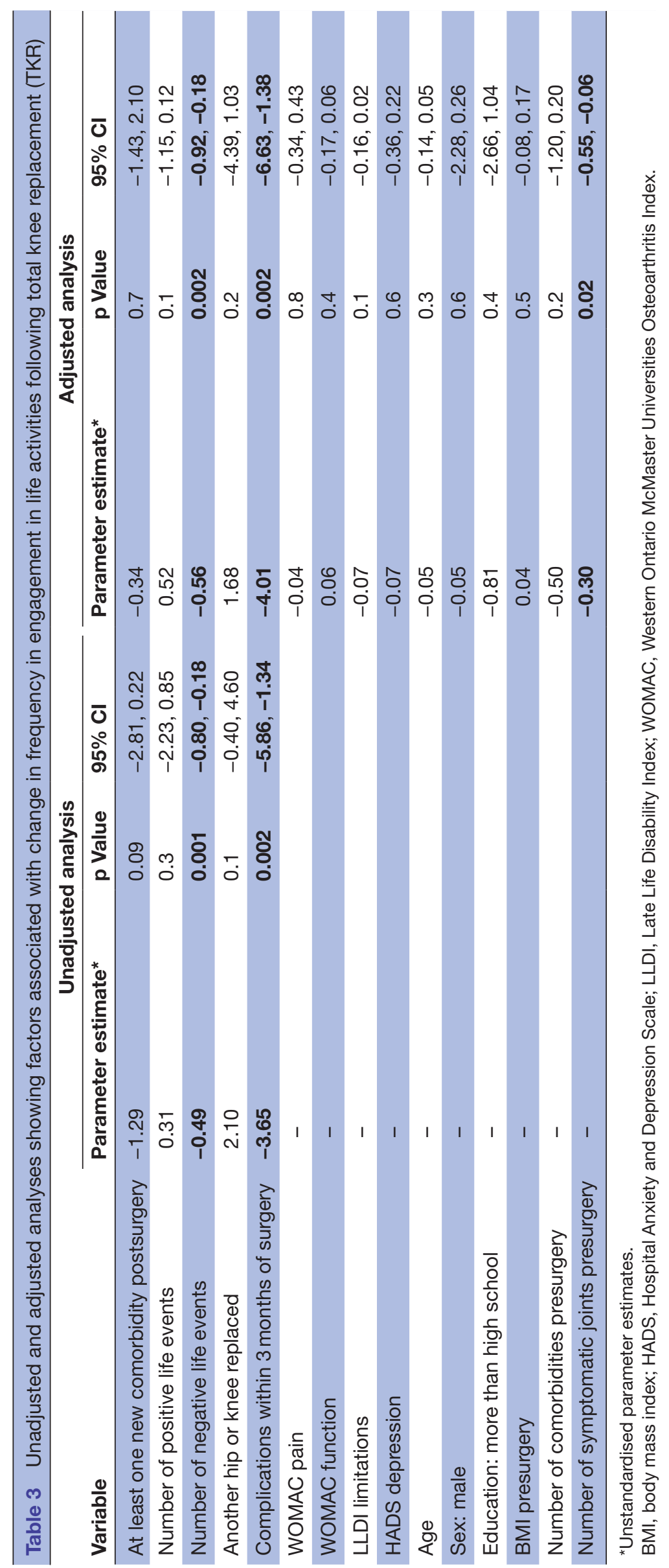


death of a partner/parent, $8.9 \%$ illness/injury and $17.3 \%$ reported family disruption over the course of their lifetime. In a study using data from the Australian Longitudinal Study of Women's Health, 28\% of 9762 mid-aged women (51-56 years) reported illness and $24.2 \%$ reported death of a close family member in a 3 -year follow-up period. ${ }^{43}$ Women aged 73-78 years or more $(\mathrm{n}=6600)$ reported experiencing death $(24.6 \%)$ or major decline in the health of a family member (17.9\%), major personal illness/injury $(13.7 \%)$ or major surgery $(13.7 \%)$ over the same period. While no data were reported for those 57-72 years of age and our data and these studies are not directly comparable, it certainly appears that life events were more frequent in our cohort in just 1 year. The reasons for this are not clear but it may reflect the immediacy of reporting in our cohort compared with the other studies, particularly as recall bias may occur as the impact of events may diminish over time or they may be forgotten.

The complexity related to individual life events was evident in that the same life event (eg, change in work situation or retirement might be perceived as either desirable or negative) was perceived as positive by some and negative by others, likely reflecting the life context within which the event occurred or whether or not it was chosen or imposed. In contrast, the majority of serious illness/ injury to self, family, close friend and major changes in financial situation and social activities seemed to be perceived as having a negative impact. Much of the literature related to life events, particularly in people with arthritis, focuses on how stressful life events are experienced, often evaluating how personality or coping impact their interpretation. ${ }^{44-46}$ Our study suggests that other life factors also may play a role in why the same event is perceived as positive or negative.

Additionally, it is not surprising that a surgical complication and other symptomatic joints influenced change in frequency of engagement after TKR surgery. Although complications occurred in a small number of people, they can be devastating, particularly if an infection requires the prosthesis to be removed. Also, $\mathrm{OA}$ is a chronic condition, rarely limited to a single joint, with symptoms common in knees, hips, the spine and hands such that limited mobility, disability and limited engagement in life activities are common. ${ }^{8}$ Despite TKR, people still may be experiencing symptoms in other joints that limit their engagement.

Although new health problems over and above surgical complications were reported by $38 \%$ of participants, these health problems were not associated with change in frequency of engagement in life activities in this cohort. We were unable to identify literature that reported on the incidence of new illnesses over the course of a year. Given the increasing prevalence by age for many chronic conditions and that peak prevalence often occurs in an age range similar to the majority of our cohort, ${ }^{19}{ }^{24}$ reporting new illnesses might be expected. We also acknowledge that comorbidity reporting is challenging and work is required to understand how best to represent clusters of diseases and the impact of severity on outcome in people with multimorbidity.
Given the impact of limited mobility and activity on the development and control of chronic conditions ${ }^{9} 10$ and the importance of engagement in life activities for healthy ageing, these results highlight the need for a person-centred approach that supports people in their recovery from TKR. Importantly, this support should likely continue postsurgery beyond traditional interventions that focus on shorter-term symptom control and improvements in physical function. Additionally, if we consider that TKR is but one intervention within the trajectory of the chronic disease of $\mathrm{OA}$ and its consequences, and the evidence indicating that self-management, ${ }^{47}$ including physical activity in the context of exercise and social and leisure pursuits are critical, we would argue that these results support the need for a shift in the current paradigm of focusing on the outcome of the joint replacement surgery to a focus on the person and their circumstances and supported management of their OA overall.

In conclusion, this study, for the first time, evaluated the impact of life events, new health issues, surgical complications and having another joint replaced in people with a chronic condition, OA, during their recovery from TKR. The findings will assist clinicians in promoting and counselling patients to increase their engagement in life activities that may benefit their health and optimise their potential to manage their chronic disease considering the context of the person's life. While this study was undertaken in people with TKR, these findings likely have implications for people with other chronic conditions and their management. Future studies are needed that evaluate the person's context, particularly the relationship of life events and circumstances, in relation to the delivery processes and outcome of healthcare, to promote effective client-centred management of chronic conditions and facilitate healthy ageing.

\section{Author affiliations}

${ }^{1}$ Division of Health Care and Outcomes Research, Krembil Research Institute, University Health Network, Toronto, Canada

${ }^{2}$ Institute of Health Policy, Management and Evaluation, Dalla Lana School of Public Health, University of Toronto, Toronta, Canada

${ }^{3}$ Department of Public Health, University of Helsinki, Helsinki, Finland

${ }^{4}$ Faculty of Medicine, School of Rehabilitation, Université de Montréal, MaisonneuveRosemont Hospital Research Centre, Montréal, Canada

${ }^{5}$ Social and Behavioural Sciences Division, Dalla Lana School of Public Health, University of Toronto, Toronto, Canada

Contributors All the authors equally contributed to the conceptualisation, writing and revision of the manuscript. AMD, WV and AVP were involved in the analysis of data. $A D$ and $R W$ were responsible for the data acquisition.

Funding This study was supported by an operating grant (\#77518) from the Canadian Institutes of Health Research. LC was supported by a Post-doctoral Fellowship from the Canadian Institutes of Health Research and FW was supported by a New Investigator Award from the Canadian Institutes of Health Research at the time of this work.

Competing interests None declared.

Patient consent None.

Ethics approval University Health Network (primary) but each participating institution.

Provenance and peer review Not commissioned; externally peer reviewed. 
Data sharing statement Data are not available. These data are not publically available as there was no patient consent or ethical approval, as the ethical approval pre-dates this practice.

Open Access This is an Open Access article distributed in accordance with the Creative Commons Attribution Non Commercial (CC BY-NC 4.0) license, which permits others to distribute, remix, adapt, build upon this work non-commercially, and license their derivative works on different terms, provided the original work is properly cited and the use is non-commercial. See: http://creativecommons.org/ licenses/by-nc/4.0/

(c) Article author(s) (or their employer(s) unless otherwise stated in the text of the article) 2017. All rights reserved. No commercial use is permitted unless otherwise expressly granted.

\section{REFERENCES}

1. World Health Organization. International classification of Functioning, Disbility and Health. Geneva: World Health Organization, 2001.

2. Laine C, Davidoff F. Patient-centered medicine. A professional evolution. JAMA 1996;275:152-6.

3. Bensing J. Bridging the gap. the separate worlds of evidence-based medicine and patient-centered medicine. Patient Educ Couns 2000;39:17-25

4. Armstrong D. The invention of patient-centred medicine. Social Theory \& Health 2011;9:410-8.

5. van Mossel C, Alford M, Watson $\mathrm{H}$. Challenges of patient-centred care: practice or rhetoric. Nurs Inq 2011;18:278-89.

6. Ward BW, Schiller JS, Goodman RA. Multiple chronic conditions among US adults: a 2012 update. Prev Chronic Dis 2014;11:E62.

7. Report of the Advisory Panel on Healthcare Innovation. UNLEASHING INNOVATION: excellent Healthcare for Canada. chapter 11: concluding Summary. 2015 http://www.hc-sc.gc.ca/hcssss/innovation/index-eng.php (accessed $30 \mathrm{Jul}$ 2015).

8. Centers for Disease Control and Prevention (CDC). Arthritis as a potential barrier to physical activity among adults with heart disease-United States, 2005 and 2007. MMWR Morb Mortal Wkly Rep 2009;58:165-9.

9. Nüesch E, Dieppe P, Reichenbach S, et al. All cause and disease specific mortality in patients with knee or hip osteoarthritis: population based cohort study. BMJ 2011;342:d1165.

10. Hawker GA, Croxford R, Bierman AS, et al. All-cause mortality and serious cardiovascular events in people with hip and knee osteoarthritis: a population based cohort study. PLOS One 2014;9:e91286.

11. Schieir O, Hogg-Johnson S, Glazier RH, et al. Sex Variations in the effects of Arthritis and Activity Limitation on First Heart Disease Event occurrence in the Canadian General Population: results from the Longitudinal National Population Health Survey. Arthritis Care Res 2016;68:811-8.

12. Fortin PR, Penrod JR, Clarke AE, et al. Timing of total joint replacement affects clinical outcomes among patients with osteoarthritis of the hip or knee. Arthritis Rheum 2002;46:3327-30.

13. Jones CA, Beaupre LA, Johnston DW, et al. Total joint arthroplasties: current concepts of patient outcomes after surgery. Rheum Dis Clin North Am 2007;33:71-86.

14. Davis AM, Perruccio AV, Ibrahim S, et al. The trajectory of recovery and the inter-relationships of symptoms, activity and participation in the first year following total hip and knee replacement. Osteoarthritis Cartilage 2011;19:1413-21.

15. de Groot IB, Bussmann HJ, Stam HJ, et al. Small increase of actual physical activity 6 months after total hip or knee arthroplasty. Clin Orthop Relat Res 2008;466:2201-8.

16. Harding P, Holland AE, Delany C, et al. Do activity levels increase after total hip and knee arthroplasty? Clin Orthop Relat Res 2014;472:1502-11.

17. Paxton EW, Torres A, Love RM, et al. Total joint replacement: A multiple risk factor analysis of physical activity level 1-2 years postoperatively. Acta Orthop 2016;87(Suppl 1):44-9.

18. Smith TO, Purdy R, Lister S, et al. Living with osteoarthritis: a systematic review and meta-ethnography. Scand J Rheumatol 2014;43:441-52.

19. House JS, Umberson D, Landis KR. Structures and processes of Social support. Annu Rev Sociol 1988;14:293-318.

20. Cott CA, Gignac MA, Badley EM. Determinants of self rated health for Canadians with chronic disease and disability. J Epidemiol Community Health 1999;53:731-6.
21. Ryff CD, Singer BH. Integrating emotions into the study of social relationships and health. In: Ryff CD, Singer BH, eds. Emotion, Social Relationships, and Health. Oxford, UK: Oxford Univ, 2001.

22. Brown DW, Brown DR, Heath GW, et al. Associations between physical activity dose and health-related quality of life. Med Sci Sports Exerc 2004;36:890-6.

23. Martel L, Bélanger A, Berthelot J-M, et al. Healthy today, healthy tomorrow? findings from the National Population Health survey: healthy aging;Statistics Canada. Component of Catalogue 2005;82:618.

24. Ramage-Morin PL, Shields M, Martel L. Health-promoting factors and good health among Canadians in mid- to late life. Health Rep 2010;21:45-53.

25. Webster F, Perruccio AV, Jenkinson R, et al. Understanding participation in activity following Total Joint Replacement: a Longitudinal Qualitative Study. Osteoarthritis Cartilage 2015;23:860-7

26. Jette AM, Haley SM, Coster WJ, et al. Late life function and disability instrument: I. Development and evaluation of the disability component. J Gerontol A Biol Sci Med Sci 2002;57:M209-M216.

27. Sarason IG, Johnson JH, Siegel JM. Assessing the impact of life changes: development of the Life Experiences Survey. J Consult Clin Psychol 1978;46:932-46.

28. Sangha O, Stucki G, Liang MH, et al. The Self-Administered Comorbidity Questionnaire: a new method to assess comorbidity for clinical and health services research. Arthritis Rheum 2003;49:156-63.

29. Beckie TM. A systematic review of allostatic load, health, and health disparities. Biol Res Nurs 2012;14:311-46.

30. Seeman TE, Singer BH, Rowe JW, et al. Price of adaptation-allostatic load and its health consequences. MacArthur studies of successful aging. Arch Intern Med 1997;157:2259-68.

31. Ethgen $O$, Bruyère $O$, Richy $F$, et al. Health-related quality of life in total hip and total knee arthroplasty. A qualitative and systematic review of the literature. J Bone Joint Surg Am 2004;86-A:963-74.

32. Santaguida PL, Hawker GA, Hudak PL, et al. Patient characteristics affecting the prognosis of total hip and knee joint arthroplasty: a systematic review. Can J Surg 2008;51:428-36.

33. Bellamy N, Buchanan WW, Goldsmith $\mathrm{CH}$, et al. Validation study of WOMAC: a health status instrument for measuring clinically important patient relevant outcomes to antirheumatic drug therapy in patients with osteoarthritis of the hip or knee. J Rheumatol 1988;15:1833-40.

34. Zigmond AS, Snaith RP. The hospital anxiety and depression scale. Acta Psychiatr Scand 1983;67:361-70.

35. Berwick DM. What 'patient-centered' should mean: confessions of an extremist. Health Aff 2009;28:w555-w565.

36. Bourne RB, Chesworth B, Davis A, et al. Comparing patient outcomes after THA and TKA: is there a difference? Clin Orthop Relat Res 2010;468:542-6.

37. Bourne RB, Chesworth BM, Davis AM, et al. Patient satisfaction after total knee arthroplasty: who is satisfied and who is not? Clin Orthop Relat Res 2010;468:57-63.

38. Bradley C. Life events and the control of diabetes mellitus. J Psychosom Res 1979;23:159-62.

39. Mooy JM, de Vries H, Grootenhuis PA, et al. Major stressful life events in relation to prevalence of undetected type 2 diabetes: the Hoorn Study. Diabetes Care 2000;23:197-201.

40. Maksimovic JM, Vlajinac HD, Pejovic BD, et al. Stressful life events and type 2 diabetes. Acta Clin Belg 2014;69:273-6.

41. Gandhi R, Tso P, Davis A, et al. Outcomes of total joint arthroplasty in academic versus community hospitals. Can J Surg 2009;52:413-6.

42. Karatzias T, Yan E, Jowett S. Adverse life events and health: a population study in Hong Kong. J Psychosom Res 2015;78:173-7.

43. Brown WJ, Heesch KC, Miller YD. Life events and changing physical activity patterns in women at different life stages. Ann Behav Med 2009;37:294-305.

44. Penninx BW, van Tilburg T, Deeg DJ, et al. Direct and buffer effects of social support and personal coping resources in individuals with arthritis. Soc Sci Med 1997;44:393-402.

45. Sherman AM. Social relations and depressive symptoms in older adults with knee osteoarthritis. Soc Sci Med 2003;56:247-57.

46. Sale JE, Gignac M, Hawker G. The relationship between disease symptoms, life events, coping and treatment, and depression among older adults with osteoarthritis. J Rheumatol 2008;35:335-42.

47. Brady TJ, Murphy L, O'Colmain BJ, et al. A meta-analysis of health status, health behaviors, and healthcare utilization outcomes of the chronic disease self-management program. Prev Chronic Dis 2013;10:120112. 